\title{
Corino de Andrade disease: mechanisms and impact on reproduction
}

\author{
Rita A Lopes ${ }^{1}$, Teresa Coelho², Alberto Barros ${ }^{3,4}$, Mário Sousa ${ }^{1}$ \\ ${ }^{1}$ Laboratory of Cell Biology, Department of Microscopy, Institute of Biomedical Sciences Abel Salazar (ICBAS), \\ University of Porto, Portugal \\ 2 Department of Neurophysiology, Research Center of Corino de Andrade (Paramyloidosis), Hospital Centre of \\ Porto, Portugal \\ ${ }^{3}$ Centre for Reproductive Genetics Prof. Alberto Barros (CGR), Porto, Portugal \\ ${ }^{4}$ Department of Genetics - School of Medicine, Institute of Health Research and Innovation, University of Porto
}

\begin{abstract}
Familial amyloid polyneuropathy was first described by Corino de Andrade in 1952 in Northern Portugal. It is a fatal autosomal dominant neurodegenerative disorder characterized by a progression of neurologic symptoms, beginning early in the reproductive life. The Transthyretin gene mutation originates a mutated protein that precipitates in the connective tissue as amyloid deposits. This disease is presently named Transthyretin-related hereditary amyloidosis. We performed an extensive review on this disease based on searches in Medical databases and in paper references. In this review, we briefly summarize the epidemiology and the mechanisms involved on amyloid deposition; we detailed how to evaluate the mechanisms implicated on the development of the major signs and symptoms associated with reproductive dysfunction; and we discuss the mechanisms involved in secondary sexual dysfunction after psychological treatments. Treatment of the disease is directed towards relieving specific symptoms in association with liver transplant, and molecular and genetic therapeutics. Although the current clinical trials indicate symptoms relief, no data on the reproductive function was reported. Thus, preimplantation genetic diagnosis is presently the only available technique that eradicates the disease as it avoids the birth of new patients.
\end{abstract}

Keywords: Transthyretin-related hereditary amyloidosis, physiopathology, genetics, sexual dysfunction, therapy, in vitro fertilization

\section{INTRODUCTION}

Familial amyloid polyneuropathy was first described in 1952 by Corino de Andrade in Northern Portugal (Andrade, 1952); being presently named Transthyretinrelated hereditary amyloidosis (V30M). It is a chronic fatal hereditary autosomal dominant neurodegenerative disorder, with a high prevalence in that endemic region $(1: 1000)$. The progressive sensory, autonomic and motor neuropathies eventually leads to cachexia and/or cardiovascular collapse, and results in death 10-20 years after the onset of symptoms (Sousa et al., 1995; Ando et al., 2013). It is caused by a single nucleotide mutation in the Transthyretin (TTR) gene (Saraiva et al., 1984; Benson \& Kincaid, 2007).

Most of the affected individuals are heterozygous and thus express both normal and variant TTR. Although carriers of the mutation have a circulating mutant protein since fetal life, no toxic amyloid deposition occurs until adulthood. This disease is thus mainly diagnosed in young adults (high penetrance) with less than 40 years of age (early-onset), at a similar gender-wise ratio. In these patients, $60 \%$ develop symptoms between $25-35$ years and $87 \%$ before 40 years of age (Saraiva et al., 1984; Benson \& Kincaid, 2007; Ando et al., 2013). In regions outside the endemic area, the V30M mutation has a late-onset (after 50 years of age) of symptoms (reduced penetrance) and some individuals may remain asymptomatic for life. Patients are thus frequently diagnosed after having achieved a natural conception (Sousa et al., 1995; Coelho et al., 1994; Soares et al., 1999, 2004, 2005).

\section{Molecular mechanisms involved in amyloid} deposition, toxic effects and tissue specificity

The gene that codes for the TTR protein is located on chromosome 18. Transthyretin is the plasma transport protein for thyroid hormone thyroxin and retinol-binding protein/vitamin A. It is made of four monomers that associate into dimers and then into a tetramer. Although mainly produced by hepatocytes, it is also synthesized in the retinal pigment epithelium of the eye and in the ventricular choroid plexus of the brain. The TTR protein does not cross the blood-brain barrier (BBB) and the concentrations found in the cerebrospinal fluid (CSF) are much higher than those in the plasma (Saraiva et al., 1984, 1985; Coelho et al., 1994; Hou et al., 2007; Teixeira et al., 2013).

The mutated TTR is originated from a missense point mutation in exon 2, that causes the replacement of amino acid valine for methionine at position 30 . This causes a conformational change whose instability facilitates the dissociation of the tetramer into monomers. Monomers then precipitate in the loose connective tissue and progressively self-assemble into amyloid fibrils (Costa et al., 1978; Saraiva et al., 1984, 1985; Benson \& Kincaid, 2007; Hou et al., 2007; Planté-Bordeneuve \& Said, 2011; Gasperini \& Small, 2012; Teixeira et al., 2013). Precipitated monomers interact with the cytoplasmic membrane of Schwann cells (Figure 1), causing calcium influx, and this intracellular increase in calcium induces the release of further calcium from calcium stores. The high level of intracellular calcium is toxic and promotes an increase in free oxygen radical concentration, which then causes membrane lipid peroxidation. This is followed by the activation of apoptosis mechanisms. Additionally, abnormal TTR also precipitates in the loose connective tissue of endoneurium capillaries (Figure 1), causing similar injury cell events. Injured Schwann cells and endothelial cells then activate an inflammatory response. All the phenomena lead to progressive demyelination and neuron loss, which is aggravated by nerve ischemia due to a compression effect (Sousa et al., 2001, 2004; Teixeira et al., 2006; Benson \& Kincaid, 2007; Hou et al., 2007; Planté-Bordeneuve \& Said, 2011; Gasperini \& Small, 2012).

The disease initiates in the peripheral nervous system (PNS). The mutated protein in the PNS originates in the circulation and by CFS diffusion. Since the blood-nerve barrier (BNB) is much weaker than the BBB, TTR can easily traverse the BNB (Sousa et al., 2004). In addition, TTR expression was also found in Schwann cells, which would enable PNS direct attainment (Murakami et al., 2010). It is suspected that cells more resistant to amyloid deposition 


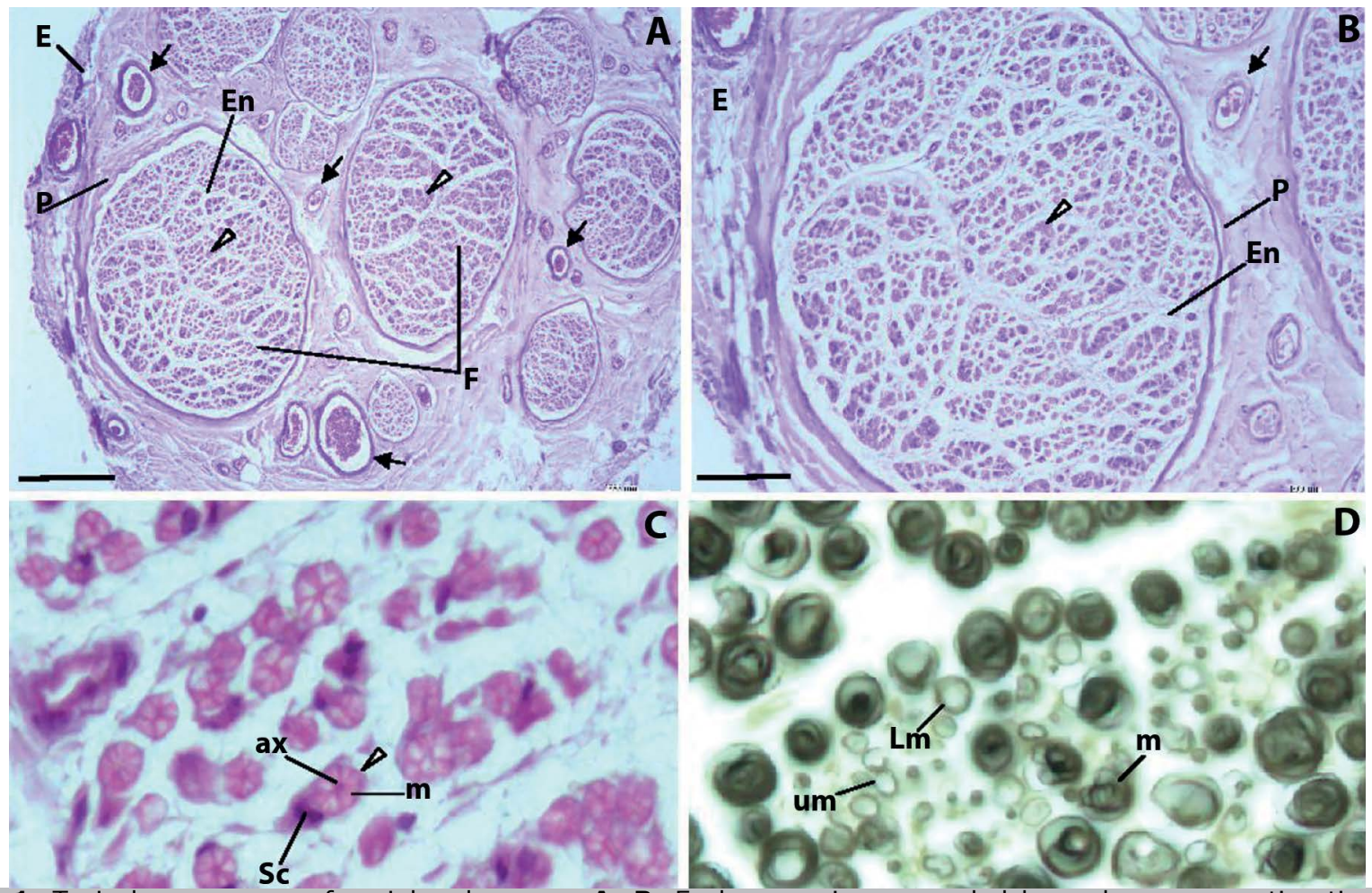

Figure 1. Typical appearance of peripheral nerves. A, B. Each nerve is surrounded by a dense connective tissue, the epineurium (E). Nerves are a group of nerve fibers (arrowheads) disposed into different size aggregates - the nerve fascicles (F). Nerve bundles are separated by loose connective tissue, the perineurium (P). Numerous blood vessels (arrows) can be seen in the perineurium. Each bundle presents numerous axons surrounded by loose connective tissue, the endoneurium (En). In myelinated axons, Schwann cells develop thin cytoplasmic extensions that wrap over the axon surface, creating the myelin sheath. The cytoplasmic membrane of the Schwann cell is tightly connected to the axon cytoplasmic membrane, controlling axon metabolism through transmembrane channels and $\mathrm{pH}$, providing the ATP necessary for kinesin-continued transport of neurotransmitter vesicles along microtubules, and scavenging free toxic oxygen radicals produced during electric impulses. The myelin layer is a barrier to most molecules, and only very small liposoluble molecules can traverse the myelin sheath. C. In myelinated axons, each nerve fibber consists of an axon (ax) surrounded by the myelin sheath ( $\mathbf{m}$ ) of Shawn cells (Sc). Unmyelinated axons are nevertheless surrounded by Schwann cells. D. Myelinated fibers ( $\mathbf{m}$ ), light myelinated fibers ( $\mathbf{L m})$ and unmyelinated fibers (um). A-C. Sural nerve, Hemalumen-eosin. D. Sciatic nerve, Osmic acid. Bars: A: 200 $\mu \mathrm{m}$; B: $100 \mu \mathrm{m} ; \mathrm{C}: 9 \mu \mathrm{m} ; \mathrm{D}: 9 \mu \mathrm{m}$.

are surrounded by less connective tissue and/or have larger defense mechanisms, as in hepatocytes, the main site of TTR synthesis. On the contrary, axons are surrounded by large amounts of loose connective tissue and have poor defense mechanisms. The beginning of symptoms in the body extremities can thus be explained by the fact that these axons are very long and distant from the neural cell bodies (lack of the appropriate antioxidant systems needed to defend against peroxide membrane damage) and present more small myelinated and unmyelinated fibers (less myelin protection) (Sousa et al., 2004).

\section{Molecular mechanisms of the disease}

V30M affects both branches of the PNS, somatic and autonomic, with different nerve fibers being affected at different stages of the disease. In the early stages, the smaller nerve fibers (small myelinated and unmyelinated), which mediate pain, thermal sensation and autonomic function, are affected. As the disease moves on to more advanced stages, the larger myelinated fibers (large nerve fibers are heavily myelinated and mediate motor strength, vibratory and touch sensation) start being impaired and destroyed. As the function of the limbs deteriorates, the autonomic nervous system also becomes impaired by amyloid deposition. Early symptoms correspond to neurogenic digestive disturbances. With time, patients refer that all they eat is immediately evacuated, which leads to cachexia (Andrade, 1952; Coelho et al., 1994; Benson \& Kincaid, 2007; Hou et al., 2007; Planté-Bordeneuve \& Said, 2011; Ando et al., 2013).

Besides peripheral neuropathy and gastrointestinal impairment, other clinical problems originate from V30M. Orthostatic hypotension (Benson \& Kincaid, 2007; PlantéBordeneuve \& Said, 2011; Ando et al., 2013), Nephropathy (Lobato et al., 2003; Benson \& Kincaid, 2007; Lobato \& Rocha, 2012; Planté-Bordeneuve \& Said, 2011; Ando et al., 2013), Ocular diseases (Benson \& Kincaid, 2007; CunhaVaz, 2009; Beirão et al., 2012, 2013; Planté-Bordeneuve \& Said, 2011; Ando et al., 2013), Heart diseases (Benson \& Kincaid, 2007; Planté-Bordeneuve \& Said, 2011; Ando et al., 2013), and reproductive problems.

\section{Problems related to the reproductive system}

Patients with V30M develop sexual impairments due to psychological and physical problems, with the latter being related to peripheral nerve loss and vascular ischemia. Sexual responses (Figure 2) are mediated by the coordinated action of the PNS: sympathetic, parasympathetic and somatic sensory nerves. They have two synapses. The first synapse links preganglionic neurons (in the spine) to postganglionic neurons (adjacent to the spine), which is mediated by the neurotransmitter acetylcholine that 
acts over nicotinic receptors. The second synapse links postganglionic neurons to the target tissue, being mediated by neurotransmitters norepinephrine/noradrenaline (or epinephrine/adrenaline), that act on adrenergic receptors. Parasympathetic nerves have their postganglionic ganglia in the pelvis. The neurotransmitter is acetylcholine, that acts on cholinergic receptors in target tissues. Vascular arterial dilation (penis and clitoris erection) depend of parasympathetic nerves, with a simultaneous relaxation of smooth muscles of the venous (cavernous) sinusoids by means of nitric oxide. The parasympathetic nerves also stimulate the vas deferens, seminal vesicles, prostate and vaginal glands. The pelvic splanchnic nerve is formed by the parasympathetic nerves from the sacral S2-S4 levels of the spinal cord (preganglionic neurons) (Meston, 2000; Kandeel et al., 2001; McKenna, 2002; Bancroft, 2005; Krüger et al., 2005; Azadzoi \& Siroky, 2010; Andersson, 2011; Tezer et al., 2012; Alwaal et al., 2015).

Whereas Reflex Erection arises from direct stimulation of the penis and is mediated by parasympathetic nerves, Psychogenic Erection is mediated by sympathetic nerves. Stimulation of sexual male glands secretion and vaginal secretion is also controlled by parasympathetic nerves. Emission involves the release of sperm through contraction of the gonadal ducts and the sexual glands, and is controlled by sympathetic nerves (the hypograstric nerve is formed by the sympathetic nerves from the thoracic T11 level up to the lumbar L2 level of the spinal cord at preganglionic neurons). Uterus, cervix and vagina contractions are also controlled by sympathetic nerves. Smooth muscle contraction of the vas deferens during ejaculation (release of sperm through the urethra) and vaginal contractions during orgasm, as well as the contractions of the somatic pelvic muscles that accompany the orgasm, are controlled by the sacral spinal nerves (the pudendal nerve is formed by the spinal nerves from the sacral S2-S4 levels of the spinal cord), that in turn convey the genital perineal sensations to the brain (efferent and afferent sensory-motor fibers) (Meston, 2000; Kandeel et al., 2001; McKenna, 2002; Bancroft, 2005; Krüger et al., 2005; Azadzoi \& Siroky, 2010; Andersson, 2011; Tezer et al., 2012; Alwaal et al., 2015).

Arousal means a psychological sexual anticipation. Male arousal leads to erection, whereas in females the arousal response is reflected in engorged sexual tissues such as nipples, vulva, clitoris, vaginal walls and vaginal lubrication. Mental stimuli and physical stimuli such as touch, and the internal fluctuation of hormones can influence sexual arousal. Sexual dysfunction includes any problem experienced by either member of the couple during the sexual act that prevents them from having a pleasant and positive sexual experience (Meston, 2000; Kandeel et al., 2001; McKenna, 2002; Bancroft, 2005; Krüger et al., 2005; Azadzoi \& Siroky, 2010; Andersson, 2011; Tezer et al., 2012; Alwaal et al., 2015).

In V30M patients, sexual dysfunction is believed to be associated with problems concerning the autonomic nervous system, followed by psychogenic responses. In men, the most common abnormalities related to the reproductive system are erectile dysfunction and retrograde ejaculation. Normally, the urethral sphincter contracts before ejaculation forcing the semen to exit via the urethra. When the sphincter does not function properly, retrograde ejaculation may occur, with semen being introduced into the bladder. The urethral sphincter is composed of smooth muscle and is thus controlled by the autonomic nervous system. The sympathetic nervous system maintains tonic contractions of the urethral muscle, whereas the parasympathetic nervous system relaxes the urethral sphincter muscle during micturition. The parasympathetic activity is responsible for bladder contraction and enables the urethral sphincter to open and urine to be expelled into the urethra. The sympathetic activity leads to contraction and closure of the sphincter. Moderate bladder distension inhibits parasympathetic activity to enable the bladder to be normally filled. When the bladder is full, the afferent activity conveys this information to the brain and this leads to an increase of the parasympathetic tone, together with a decrease in sympathetic activity, causing the urethral sphincter muscle to relax and the bladder to contract, which is followed by micturition (Hita Villaplana et al., 1977; Jung et al., 2012).

In men, erectile dysfunction (controlled by parasympathetic nerves) can be one of the first signs of V30M (Andrade, 1952), and it is also related to the autonomic neuropathy. Problems in ejaculation (controlled by sympathetic nerves) can also be present. Besides retrograde ejaculation (see above) they can also develop secretory azoospermia due to atrophy of the seminiferous tubules, caused by amyloid deposits in the interstitial loose connective tissue around small vessels (Andrade, 1952). These men need psychological support, and there are several drugs that help in erection.

Female Sexual dysfunction affects about $42 \%$ of V30M patients. It is due to pelvic nerve injury (neuropathy) caused by destruction of genital myelinated fibers. In this area, amyloid deposition induces nerve loss and decreased blood flow (amyloid causes vessel degeneration) (Alves et al., 1997; Gomes et al., 2011, 2012; Oliveira-e-Silva et al., 2013). Among the symptoms associated with this condition there are reductions on the number of sexual stimuli received by the individual, lubrication deficiencies, lack of sexual desire (due to difficulties in peripheral stimulation) and arousal, painful intercourse, difficulties concerning orgasms and sexual dissatisfaction. More specifically, there is decreased genital area sensation (decreased sexual pleasure stimulation feelings), clitoral blood flow (decreased erection and sensibility; decreased vaginal congestion and dilation), contractile capacity (decreased uterine and vaginal contractions), and glandular secretion (decreased lubrication causes genital discomfort). Recurrent urinary tract infections, vaginal and uterus prolapse, and urinary incontinence - namely coital urinary incontinence (due to detrusor hypo-contractility by loss of parasympathetic nerve stimulation of this smooth muscle of the bladder wall), aggravate the loss of sexual drive (decreased mental arousal), and thus appear associated with dyspareunia (painful intercourse) and sexual dissatisfaction. These patients need psychological support, and there are several pelvic and vaginal therapies that should be introduced, besides surgical corrections of prolapses and incontinence (Gomes et al., 2011, 2012).

Sexual dysfunction is directly associated to disease stage and can be aggravated by the medication taken by the patients. Known medications with a negative impact on sexual function are anti-depressives, anxiolytics, antiepileptics and anti-hypertensives. Affected patients become psychological fragile, as they know they have a potential fatal disease and they are not sexually satisfactory to their partner. This causes loss of sexual motivation as they feel less feminine/masculine, that their body is damaged, unhappy, frustrated, shame, self-image degradation, and failure to meet personal expectations.

Several medications are used to counteract these psychological problems, but on the other hand there are side-effects reflecting on sexual performance. Anxiolytics stimulate gamma-aminobutyric receptors (GABA), and sexual side-effects include decreased libido (decreased gland secretion) and erection (penis and clitoris), which is accomplished through anticholinergic (parasympathetic 
Arousal -Excitation

Skin tactile sensation at upper and lower genitals, perineum and anal region-

Spinal nerves (SN), melanocortin

Increased muscle tension-SN

Increased blood pressure-smooth muscle contraction-vasoconstriction-sympathetic nerves (SP)

Increased breath frequency-balance between parasympathetic nerves (PS) and SP.

During inspiration the PS causes vasodilation and bronchial tree dilation, simultaneously with tachycardia (SP)

During expiration there is bradycardia (PS) and constriction of the bronchial tree (SP)

Increased oxygen consumption-

smooth muscle relaxation-dilation of the bronchial tree; increased breath frequency-PS, SP

Increased sweating-increased gland secretion-PS

Body hair erection-smooth muscle contraction-SN, SP

Skin flush-smooth muscle relaxation-vasodilation-PS

Strained (tense) and prominent areola-smooth muscle contraction- $\mathrm{SN}$, SP

Hardening and erection of neeples

smooth muscle contraction-SN, SP

blood vessels smooth muscle relaxation with vessel ingurgitation-PS, nitric oxide (NO), oxytocin

The breast become fuller (increase volume) and firm-blood vessels smooth muscle relaxationvasodilation-PS

Tighten (retraction) of the scrotum-SN

The testis swell-blood vessels smooth muscle relaxation-vasodilation-PS

The labia minora swell-smooth muscle relaxation-vasodilation-PS

The vaginal walls swell-smooth muscle relaxation-vasodilation-PS

The clitoris swell (beginning of Erection)-

smooth muscle relaxation of venus sinusoids and ingurgitation-PS, NO, oxytocin, melanocortin

The penis swell (beginning of Erection)

smooth muscle relaxation of venus sinusoids and ingurgitation-PS, NO, oxytocin, testosterone

Increased gland secretion of male ducts: epididymis, vasa deferens, seminal vesicles, prostate, urethra with liberation of a lubricating fluid-urethral lubrication-PS, vasoactive mediators

Increased vaginal secretion-vaginal lubrication-PS, vasoactive mediators, oxytocin, estradiol

Plateau - Maximum

Increase of the above mentioned body change

Muscle spasm in feet, hands and face

Emission - Ejaculation - Orgasm

Increase of the above mentioned body changes

Smooth muscle contraction of male genital ducts-expel of semen up to the posterior urethra-Emission-SP

Rytmic contractions of the base of the penis-Ejaculation-SN-Orgasm-oxytocin, prolactin

Involuntary muscle contraction of anal external sphincter and urethral external sphincter-PS, SP

Rytmic contractions of the pelvic muscles, uterus and vagina-SN-Orgasm-oxytocin, prolactin

Smooth muscle contraction of vagina, cervix and uterus-SP

Figure 2. Phases of the sexual response. Control mechanisms by the peripheral nervous system, somatic and autonomic (sympathetic and parasympathetic). 
nerves: erection, gland secretion) and antiadrenergic (sympathetic nerves: orgasm) effects (Tallman et al., 2002). Anti-depression agents increase serotonin activity, which inhibits acetylcholine and norepinephrine receptors, thus inhibiting their functions in arousal, erection and orgasm; they have anticholinergic effects (involved in erection, male and vaginal lubrication); they cause dopamine blockade (dopamine increases sexual arousal and enhance penile erection); nitric oxide inhibition (involved in erection); and increase prolactin secretion (loss of male arousal, erection, orgasm, retrograde ejaculation: hyperprolactinemia impairs luteinizing hormone (LH) release, which causes decreased testosterone production, blocks dopamine actions, increases serotonin secretion and blocks adrenergic receptors) (Baldwin \& Mayers, 2003; Buvat, 2003). Antiepileptics are used to treat sensitive disorders and pain, with side-effects causing loss of sexual drive, arousal, erection, gland secretion and orgasm. Gabapentin and Pregabalin are anticonvulsants used to treat neuropathic pain. Although they stimulate GABA actions, their main action is to bind to voltage-gated $\mathrm{Ca}^{2+}$ channels of synapses, inhibiting neurotransmitter release in spinal cord neurons (Kaufman \& Struck, 2011). Antihypertensives can also cause sexual dysfunction as a sideeffect. The effects on erection are supposed to derive from vascular supply impairment and vascular smooth muscle contraction; of adrenergic receptors block (sympathetic nerves: emission and contraction); and cholinergic receptors block (parasympathetic nerves: erection and gland secretion). Some also alter serotonin action (Manolis \& Doumas, 2012; Nunes et al., 2012).

\section{Medical interventions to avoid disease transmission \\ Current V30M treatments are directed towards relieving specific symptoms, such as pain, infections, cardiovascular problems, kidney failure, bladder dysfunction and genital problems. However, efforts have been made to develop new treatment modalities in order to eradicate or halt the progression of the disease.}

\subsection{Preimplantation genetic diagnosis}

Given that this disease is hereditary and autosomal dominant, each patient has at least one parent suffering from the condition. As the great majority of the carriers are heterozygotes for the disease, they have a $50 \%$ chance of passing it on to their children if only one parent is affected or a $75 \%$ chance when both parents are affected. Besides social teaching (couple decision to avoid conception), the only way to halt transmission of the disease is the medical termination of pregnancy after a positive Prenatal diagnostic test (Yamashita et al., 2009) or embryo selection after preimplantation genetic diagnosis (PGD) (Carvalho et al., 2001; Almeida et al., 2005; Valdrez et al., 2014).

The PGD technique enables the detection of the genetic defect in embryos conceived by intracytoplasmic sperm injection, and thus enables to choose the nonaffected embryo for uterine transfer. Preimplantation genetic diagnosis (Figure 3 ) is performed following a sequence of delicate steps. First, the woman is treated with subcutaneous administration of a gonadotrophinreleasing hormone antagonist, to suppress ovary function. Growth of several early antral follicles is then stimulated with recombinant follicle-stimulating hormone (Pinto et al., 2009). It takes around 8-10 days for the follicles to reach $17 \mathrm{~mm}$. When they reach this size, the patient is injected with human chorionic gonadotrophin (HCG) to stimulate the final oocyte maturation and simulate the LH peak. Up to 36 hours after this procedure, follicles are aspirated from the ovary by guided ultrasound. Now, the woman is also given endovaginal progesterone pills to enable endometrium differentiation and induce an implantation window.

Aspirated follicles are incubated for $2 \mathrm{~h}$ and then cumulus cells are removed by hyaluronidase treatment. After $2 \mathrm{~h}$ of incubation, denuded oocytes are microinjected with a selected sperm (Tesarik et al., 1994; Tesarik \& Sousa, 1995). Sperm are obtained by masturbation (ejaculate), urine collection (in retrograde ejaculation), electroejaculation (in anejaculation) (Barros et al., 1998), or testicular aspiration (in azoospermia or when the quality of sperm retrieved by the other methods is insufficient) (Sousa et al., 2002). After collection, sperm is submitted to a differential gradient centrifugation to select the most morphological normal sperm (simulates vaginal and cervix selection). Then, sperm are incubated in capacitating medium (simulates uterine milieu) and after $1 \mathrm{~h}$ the most morphological normal and rapid progressive sperm are chosen for injection. Microinjection is performed in an inverted microscope with a heated stage, one spermatozoon per oocyte (Figure 3 ).

After microinjection, oocytes are incubated in sequential embryo culture media (simulates tubar and uterine milieu). The day after injection, oocytes are observed to select those which are normally fertilized (presence of two polar bodies and two pronuclei, which indicates oocyte activation and meiosis completion by the oocyte). When embryo development is normal, at day 2 they show 2-4 blastomeres and at day 3 they will present 6-8 cells (Vandervorst et al., 1998). Only day 3 embryos with less than $25 \%$ of fragments and with similar sized blastomeres are selected for embryo biopsy. Embryo biopsy is performed in the inverted microscope. A hole on the oocyte zona pellucida is obtained with the assistance of a computer-controlled laser beam. After that, a biopsy micropipette enters the perivitelline space and aspirates 1-2 blastomeres (Figure 3 ). While the embryo returns to the incubator, each blastomere is transferred to a PCR tube and transported to a Genetic reference laboratory. There, the DNA of each blastomere is isolated and the mutation is screened. After two days, the genetic result is given (Carvalho et al., 2001). At that time (day 5 after fertilization), cultured viable embryos have developed to the blastocyst stage (Gardner et al., 2000). Only those blastocysts with absent mutation are transferred to the uterine cavity. Alternatively, embryo biopsy can be performed at the blastocyst stage (trofectoderme biopsy) and embryos are frozen. After the genetic result, blastocysts are thawed and transferred in a natural cycle. Presently, blastocyst biopsy is the preferable approach in cases when at least four high quality embryos are obtained at day 3 of culture (Figure 4). Pregnancy is evaluated by the rise of serum $\beta$-HCG about 12 days after embryo transfer. Overall, the live-birth delivery rate is about $48 \%$.

This procedure has proven to be quite useful for couples affected by the disease and that wish to conceive a healthy child without wanting the termination of pregnancy. These two benefits as well as avoiding the future suffering of the child are the three main reasons that lead V30M carriers to use PGD when conceiving their offspring.

\section{life \\ 4.2. Medical interventions to improve quality of \\ Except for PGD, all other techniques do not avoid the} existence of the disease but can merely slow down the production and deposition of the amyloid fibrils in the PNS of patients to improve their quality of life. These include organ transplantation (Furtado, 2000; Sousa et al., 2004; Benson \& Kincaid, 2007; Hou et al., 2007; Lobato \& Rocha, 2012; Beirão et al., 2012, 2013; Ando et al., 2013; Castaño et al., 2015), stabilizer agents (Tafamidis: prevent TTR from dissociating into monomers) (Coelho et al., 2012, 2013), 


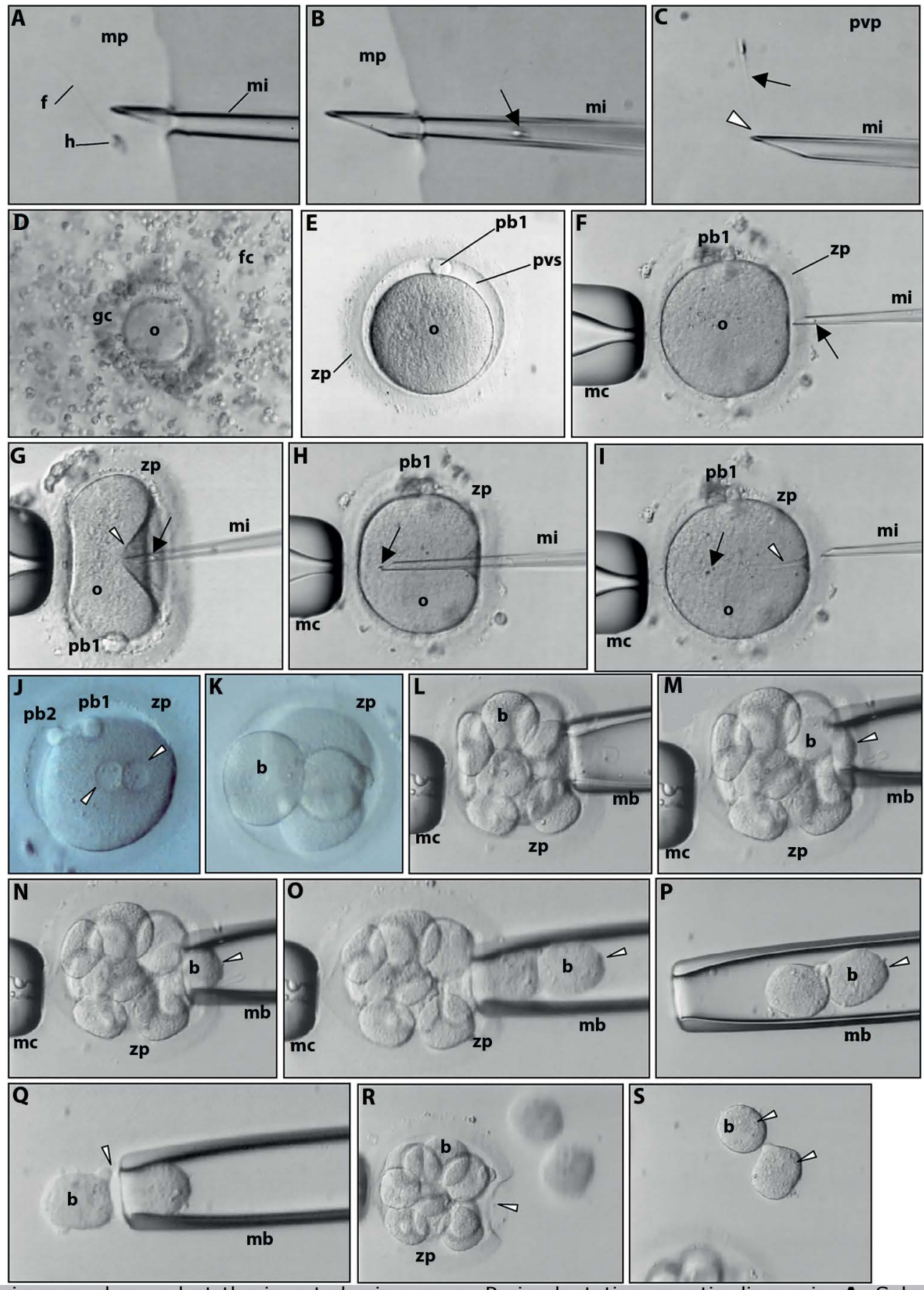

Figure 3. Live images observed at the inverted microscope. Preimplantation genetic diagnosis. A. Selection of a single, morphologically normal spermatozoon (head-h; tail-f) with a 3D forward progressive motility in culture medium (mp) supplemented with PVP to decrease spermatozoon velocity. Microinjection pipette (mi). B. Aspiration of the selected spermatozoon (arrow) into the microinjection pipette ( $\mathrm{mi}$ ). C. Immobilization of the selected spermatozoon (arrow) in PVP (pvp) by crashing (arrowhead) the distal microtubules of the flagellum. D. Cumulus-oocyte complex of the aspirated ovarian follicle. The oocyte (o) is coated by granulosa cells ( $\mathrm{gc}$ ) and encircled by follicular cells (fc) of the cumulus oophorus. E. Mature metaphase II oocyte after denudation of the cumulus and granulosa cells. Note the perivitelline space (pvs), the first polar body (pb1) and the glycoprotein oocyte coat, the zona pellucida (zp) F. For microinjection, the oocyte is held by a contention micropipette $(\mathrm{mc})$ with the first polar body at $3(\mathrm{~F})$ or $6(\mathrm{G})$ o'clock. The microinjection pipette is penetrating the zona pellucida. The spermatozoon is at the distal border of the microinjection pipette, head first (arrow). G. Penetration of the oocyte membrane (arrowhead) by the microinjection pipette. H. The spermatozoon (arrow) is released in the ooplasm. I. Extrusion of the microinjection pipette, leaving the spermatozoon in the ooplasm (arrow). The furrow of the oocyte is still visible (arrowhead). J. The day after microinjection the oocyte shows signs of normal fecundation as revealed by the presence of the second polar body (pb2) and of both pronuclei (arrowheads). K. At the second day after microinjection the zygote cleaved into an embryo with 4 blastomeres (b). L-P. Successive images of the embryo biopsy. Three days after microinjection the embryo has 8 blastomeres. After opening a small hole in the zona pellucida, the embryo biopsy pipette $(\mathrm{mb})$ enters the perivitelline space and gently aspirates two blastomeres (arrowhead). Q. Extrusion (arrowhead) of the two blastomeres to the surrounding medium. R. The embryo is left in culture with the evident zona pellucida hole (arrowhead). S. Note the nuclei of the isolated blastomeres (arrowheads). The diameter of the oocyte is about $110 \mu \mathrm{m}$. 

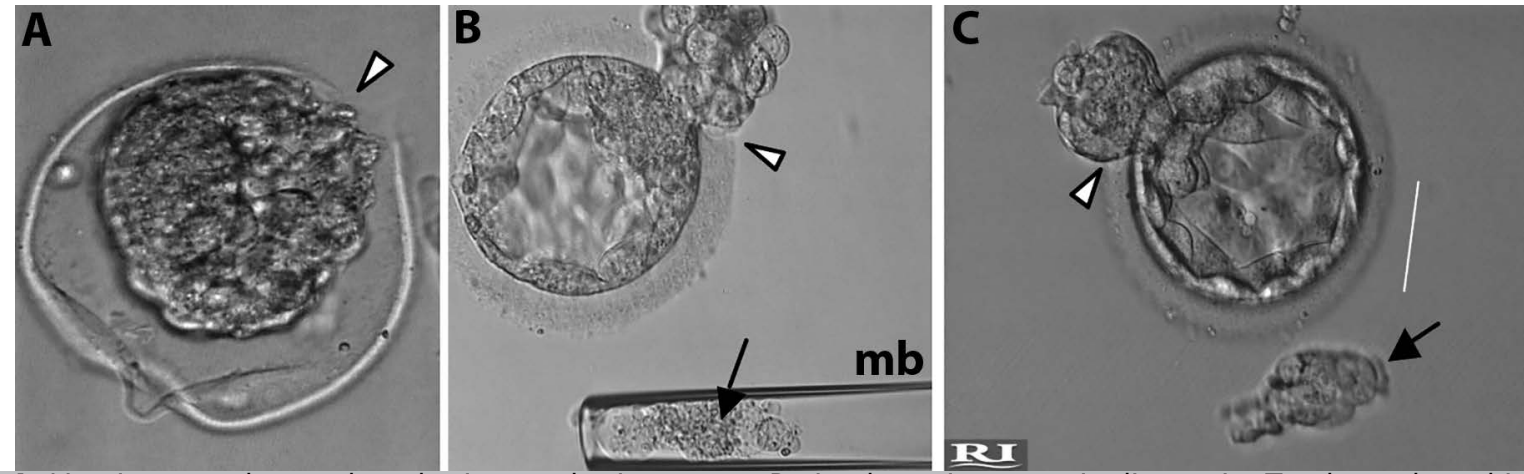

Figure 4. Live images observed at the inverted microscope. Preimplantation genetic diagnosis. Trophectoderm biopsy. A Note blastocyst retraction and the hole made by the laser beam. B. Note blastocyst expansion and the beginning of hatching (arrowhead). The biopsied cells (arrow) are inside the biopsy micropipette (mb). C. Full blastocyst expansion. Note biopsied cells (arrow) outside the biopsy micropipette.

gene therapy using antisense oligonucleotides (ASO: cause nuclear degradation of the mutated mRNA (Castaño et al., 2015; Niemietz et al., 2015), gene therapy using small interference RNA (siRNA: block translation of the mutated mRNA) (Coelho et al., 2013; Castaño et al., 2015; Niemietz et al., 2015; Wittrup \& Lieberman, 2015), and amyloid removers (Castaño et al., 2015). Transplantation did not improve erectile dysfunction but ameliorated urinary incontinence. Clinical trials with Tafamidis, ASO and siRNA revealed a significant delay in the progression of PNS symptoms but data on sexual dysfunction has not been reported. Research is in course to develop synthetic components that will be able to repair the mutated DNA. Only this technique, if administered early in life after screening, would greatly ameliorate quality of life. But to halt the disease as with PGD, it will be necessary to change the germ cell pool, and for now this is only possible in men, as they possess stem cells in the germinal epithelium.

\section{CONCLUSION}

Treatment of $\mathrm{V} 30 \mathrm{M}$ remains directed towards relieving specific symptoms in association with liver transplant, molecular and genetic therapeutics. This disease has a substantial clinical impact on reproductive performance, and current treatments do not elicit sexual improvement. Thus, PGD remains the only available technique to eradicate the disease, as it avoids the birth of new patients.

\section{ACKNOWLEDGEMENTS}

We would like to thank all other clinicians and embryologists of the Center of Reproductive Genetics Prof Alberto Barros that performed IVF patient evaluation, IVF treatments and embryo biopsy; the Biologists of the Department of Genetics School of Medicine, University of Porto for the genetic screening of blastomeres; and the other clinicians of the Hospital Centre of Porto for Transthyretin-related hereditary amyloidosis patient evaluation and treatment.

We also thank the Histology and Embryology Laboratory (ICBAS-UP) for providing us with the nerve slides from where we made Figure 1 photos.

We also would like to thank all Colleagues from the many other research articles, reviews, Book chapters and Books that we did not mention in this manuscript, but whose lecture was fundamental to the writing of the present paper.

\section{FUNDING}

No subsidies or grants contributed to this work.

UMIB is funded by National Funds through FCTFoundation for Science and Technology, under the Pest-OE/ SAU/UI0215/2014.

\section{CONFLICT OF INTERESTS}

The Authors declare that there is no conflict of interests.

\section{Corresponding author:}

Mário Sousa

Laboratory of Cell Biology, Department of Microscopy, Institute of Biomedical Sciences Abel Salazar (ICBAS), University of Porto,

Porto, Portugal;

Email: msousa@icbas.up.pt

\section{REFERENCES}

Almeida VM, Costa PM, Moreira P, Gonçalves J, Braga J. Birth of two healthy females after preimplantation genetic diagnosis for familial amyloid polyneuropathy. Reprod Biomed Online. 2005;10:641-4. PMID: 15949223 DOI: $10.1016 / \mathrm{S} 1472-6483(10) 61672-0$

Alves M, Conceição I, Luis ML. Neurophysiological evaluation of sexual dysfunction in familial amyloidotic polyneuropathyPortuguese type. Acta Neurol Scand. 1997;96:163-6. PMID: 9300069 DOI: 10.1111/j.1600-0404.1997.tb00260.x

Alwaal A, Breyer BN, Lue TF. Normal male sexual function: emphasis on orgasm and ejaculation. Fertil Steril. 2015;104:1051-60. PMID: 26385403 DOI: $10.1016 /$ j.fertnstert.2015.08.033

Andersson KE. Mechanisms of penile erection and basis for pharmacological treatment of erectile dysfunction. Pharmacol Rev. 2011;63:811-59. PMID: 21880989 DOI: 10.1124/pr.111.004515

Ando Y, Coelho T, Berk JL, Cruz MW, Ericzon BG, Ikeda SI, Lewis WD, Obici L, Planté-Bordeneuve V, Rapezzi C, Said G, Salvi F. Guideline of transthyretin-related hereditary amyloidosis for clinicians. Orphanet J Rare Dis. 2013;8:31. PMID: 23425518 DOI: 10.1186/1750-1172-8-31 
Andrade C. A peculiar form of peripheral neuropathy: familiar atypical generalized amyloidosis with special involvement of the peripheral nerves. Brain. 1952;75:40827. PMID: 12978172 DOI: $10.1093 /$ brain/75.3.408

Azadzoi KM, Siroky MB. Neurologic factors in female sexual function and dysfunction. Korean J Urol. 2010;51:443-9. PMID: 20664775 DOI: 10.4111/kju.2010.51.7.443

Baldwin D, Mayers A. Sexual side-effects of antidepressant and antipsychotic drugs. Advan Psych Treat. 2003;9:20210 DOI: http://dx.doi.org/10.1192/apt.9.3.202

Bancroft J. The endocrinology of sexual arousal. J Endocrinol. 2005;186:411-27. PMID: 16135662 DOI: $10.1677 /$ joe. 1.06233

Barros A, Sousa M, Andrade MJ, Oliveira C, Silva J, Beires J. Birth after electroejaculation coupled to intracytoplasmic sperm injection in a gun-shot spinal cord-injured man. Arch Androl. 1998;41:5-9. PMID: 9642453 DOI: $10.3109 / 01485019808988538$

Beirão M, Matos E, Beirão I, Pinho-Costa $P$, Torres P. No ocular involvement in familial amyloidotic polyneuropathy ATTR V30M domino liver recipients. Transplant Int. 2012;25:645-51. PMID: 22443165 DOI: $10.1111 / \mathrm{j} .1432-2277.2012 .01467 . x$

Beirão JM, Matos ME, Beirão IB, Costa PP, Torres PA. Topical cyclosporine for severe dry eye disease in liver-transplanted Portuguese patients with familial amyloidotic polyneuropathy (ATTRV30M). Eur J Ophthalmol. 2013;23:156-63. PMID: 23065854 DOI: $10.5301 /$ ejo.5000197

Benson MD, Kincaid JC. The molecular biology and clinical features of amyloid neuropathy. Muscle Nerve. 2007;36:41123. PMID: 17554795 DOI: 10.1002/mus.20821

Buvat J. Hyperprolactinemia and sexual function in men: a short review. Int J Impot Res. 2003;15:373-7. PMID: 14562140 DOI: $10.1038 /$ sj.ijir.3901043

Carvalho F, Sousa M, Fernandes S, Silva J, Saraiva MJ, Barros A. Preimplantation genetic diagnosis for familial amyloidotic polyneuropathy (FAP). Prenat Diagn. 2001;21:1093-9. PMID: 11746170 DOI: 10.1002/pd.250

Castaño A, Drachman BM, Judge D, Maurer MS. Natural history and therapy of TTR-cardiac amyloidosis: emerging disease-modifying therapies from organ transplantation to stabilizer and silencer drugs. Heart Fail Rev. 2015;20:16378. PMID: 25408161 DOI: 10.1007/s10741-014-9462-7

Coelho T, Sousa A, Lourenço E, Ramalheira J. A study of 159 Portuguese patients with familial amyloidotic polyneuropathy (FAP) whose parents were both unaffected. J Med Genet. 1994;31:293-9. PMID: 8071954 DOI: 10.1136/jmg.31.4.293

Coelho T, Maia LF, Martins da Silva A, Waddington Cruz M, Planté-Bordeneuve $V$, Lorezon $P$, Suhr OB, Campistol JM, Conceição IM, Schmidt HH, Trigo $P$, Kelly JW, Labaudinière R, Chan J, Packman J, Wilson A, Grogan DR. Tafamidis for transthyretin familial amyloid polyneuropathy. A randomized, controlled trial. Neurology. 2012;79:785-92. PMID: 22843282 DOI: 10.1212/WNL.0b013e3182661eb1
Coelho T, Maia LF, da Silva AM, Cruz MW, Planté-Bordeneuve $\mathrm{V}$, Suhr OB, Conceição I, Schmidt HH, Trigo P, Kelly JW, Labaudinière R, Chan J, Packman J, Grogan DR. Long-term effects of tafamidis for the treatment of transthyretin familial amyloid polyneuropathy. J Neurol. 2013a;260:2802-14. PMID: 23974642 DOI: 10.1007/s00415-013-7051-7

Coelho T, Adams D, Silva A, Lozeron P, Hawkins PN, Mant T, Perez J, Chiesa J, Warrington S, Tranter E, Munisamy M, Falzone R, Harrop J, Cehelsky J, Bettencourt BR, Geissler M, Butler JS, Sehgal A, Meyers RE, Chen Q, Borland T, Hutabarat RM, Clausen VA, Alvarez R, Fitzgerald K, GambaVitalo C, Nochur SV, Vaishnaw AK, Sah DW, Gollob JA, Suhr OB. Safety and efficacy of RNAi therapy for Transthyretin amyloidosis. N Engl J Med. 2013b;369:819-29. PMID: 23984729 DOI: $10.1056 /$ NEJMoa1208760

Costa PP, Figueira AS, Bravo FR. Amyloid fibril protein related to prealbumin in familial amyloidotic polyneuropathy. Proc Natl Acad Sci U S A. 1978;75:4499-503. PMID: 279930 DOI: http://dx.doi.org/10.1073/pnas.75.9.4499

Cunha-Vaz J. The blood-retinal barrier in retinal disease. Eur Ophthalmic Rev. 2009;3:105-8. DOI: $10.17925 / E O R .2009 .03 .02 .105$

Furtado AJL. Domino liver transplantation using livers from patients with familial amyloidotic polyneuropathy. Curr Opin Organ Transplant. 2000;5:69-73. DOI: http://dx.doi. org/10.1097/00075200-200006000-00005

Gardner DK, Lane ML, Stevens J, Schlenker T, Schoolcraft WB. Blastocyst score affects implantation and pregnancy outcome: towards a single blastocyst transfer. Fertil Steril. 2000;73:1155-8. PMID: 10856474 DOI: $10.1016 / \mathrm{S} 0015-0282(00) 00518-5$

Gasperini RJ, Small DH. Neurodegeneration in familial amyloidotic polyneuropathy. Clin Exp Pharmacol Physiol. 2012;39:680-3. PMID: 21916933 DOI: $10.1111 / \mathrm{j} .1440-1681.2011 .05607 . x$

Gomes MJ, Silva AM, Rizk DE. Familial amyloidotic polyneuropathy (Portuguese type variant I) and female pelvic floor dysfunction: a tribute to Magellan. Int Urogynecol J. 2011;22:1071-4. PMID: 21626036 DOI: $10.1007 / \mathrm{s} 00192-011-1466-4$

Gomes MJ, Martins da Silva A, Salinas J, Silva MC, Figueiredo A, Cavadas V, Coelho T. Female sexual and pelvic floor muscles dysfunctions in familial amyloidotic polyneuropathy (FAP-Portuguese type). Arch Esp Urol. 2012;65:476-88. PMID: 22619139

Hita Villaplana GH, Hita Rosino E, López Cubillana P, Asensio Egea LA, Martínez Pertusa P, Pérez Albacete M. CorinoAndrade disease (Familial amyloidotic polineuropathy type I) in Spain: urological and andrological disorders. Neurourol Urodyn. 1977;16:55-61. PMID: 9021790 DOI: 10.1002/ (SICI)1520-6777(1997)16:1<55: :AID-NAU7>3.0.CO;2-D

Hou X, Aguilar MI, Small DH. Transthyretin and familial amyloidotic polyneuropathy: Recent progress in understanding the molecular mechanism of neurodegeneration. FEBS J. 2007;274:1637-50. PMID: 17381508 DOI: $10.1111 /$ j.1742-4658.2007.05712.x 
Jung J, Ahn HK, Huh Y. Clinical and functional anatomy of the urethral sphincter. Int Neurourol J. 2012;16:102-6. PMID: 23094214 DOI: 10.5213/inj.2012.16.3.102

Kandeel FR, Koussa VK, Swerdloff RS. Male sexual function and its disorders: physiology, pathophysiology, clinical investigation, and treatment. Endocr Rev. 2001;22:34288. PMID: 11399748 DOI: 10.1210/edrv.22.3.0430

Kaufman KR, Struck PJ. Gabapentin-induced sexual dysfunction. Epilepsy Behav. 2011;21:324-6. PMID: 21612983 DOI: $10.1016 /$ j.yebeh.2011.04.058

Krüger TH, Hartmann U, Schedlowski M. Prolactinergic and dopaminergic mechanisms underlying sexual arousal and orgasm in humans. World J Urol. 2005;23:130-8. PMID: 15889301 DOI: $10.1007 / \mathrm{s} 00345-004-0496-7$

Lobato L, Beirão I, Silva M, Bravo F, Silvestre, Guimarães S, Sousa A, Noël LH, Sequeiros S. Familial ATTR amyloidosis: microalbuminuria as a predictor of symptomatic disease and clinical nephropathy. Nephrol Dial Transplant. 2003;18:5328. PMID: 12584275 DOI: 10.1093/ndt/18.3.532

Lobato L, Rocha A. Transthyretin amyloidosis and the kidney. Clin J Am Soc Nephrol. 2012;7:1337-46. PMID: 22537653 DOI: $10.2215 / C J N .08720811$

Manolis A, Doumas M. Antihypertensive treatment and sexual dysfunction. Curr Hypertens Rep. 2012;14:285-92. PMID: 22581395 DOI: 10.1007/s11906-012-0276-5

McKenna KE. The neurophysiology of female sexual function. World J Urol. 2002;20:93-100. PMID: 12107539 DOI: $10.1007 / \mathrm{s} 00345-002-0270-7$

Meston CM. Sympathetic nervous system activity and female sexual arousal. Am J Cardiol. 2000;86:30F-4F. PMID: 10899275 DOI: 10.1016/S0002-9149(00)00889-4

Murakami T, Ohsawa Y, Zhenghua L, Yamamura K, Sunada $Y$. The transthyretin gene is expressed in Schwann cells of peripheral nerves. Brain Res. 2010;1348:222-5. PMID: 20547140 DOI: $10.1016 / j$.brainres.2010.06.017

Niemietz C, Chandhok G, Schmidt H. Therapeutic Oligonucleotides Targeting Liver Disease: TTR Amyloidosis. Molecules. 2015;20:17944-75. PMID: 26437390 DOI: $10.3390 /$ molecules 201017944

Nunes KP, Labazi $H$, Webb RC. New insights into hypertension-associated erectile dysfunction. Curr Opin Nephrol Hypertens. 2012;21:163-70. PMID: 22240443 DOI: $10.1097 / \mathrm{MNH} .0 \mathrm{~b} 013 \mathrm{e} 32835021 \mathrm{bd}$

Oliveira-e-Silva T, Campos Pinheiro L, Rocha Mendes J, Barroso E, Monteiro Pereira N. Peripheral polyneuropathy and female sexual dysfunction-familial amyloidotic polyneuropathy as an example besides diabetes mellitus. J Sex Med. 2013;10:430-8. PMID: 23217031 DOI: $10.1111 /$ jsm. 12013
Pinto F, Oliveira C, Cardoso MF, Teixeira-da-Silva J, Silva J, Sousa M, Barros A. Impact of GnRH ovarian stimulation protocols on intracytoplasmic sperm injection outcomes. Reprod Biol Endocrinol. 2009;7:5. PMID: 19146685 DOI: 10.1186/1477-7827-7-5

Planté-Bordeneuve $\quad V$, Said G. Familial amyloid polyneuropathy. Lancet Neurol. 2011;10:1086-97. PMID: 22094129 DOI: 10.1016/S1474-4422(11)70246-0

Saraiva MJ, Birken S, Costa PP, Goodman DS. Amyloid fibril protein in familial amyloidotic polyneuropathy, Portuguese type. Definition of molecular abnormality in transthyretin (prealbumin). J Clin Invest. 1984;74:104-19. PMID: 6736244 DOI: $10.1172 /$ JCI111390

Saraiva MJ, Costa PP, Goodman DS. Biochemical marker in familial amyloidotic polyneuropathy, Portuguese type. Family studies on the transthyretin (prealbumin)methionine-30 variant. J Clin Invest. 1985;76:2171-7. PMID: 3908483 DOI: 10.1172/JCI112224

Soares M, Buxbaum J, Sirugo G, Coelho T, Sousa A, Kastner D, Saraiva MJ. Genetic anticipation in Portuguese kindreds with familial amyloidotic polyneuropathy is unlikely to be caused by triplet repeat expansions. Hum Genet. 1999;104:480-5. PMID: 10453736 DOI: $10.1007 / \mathrm{s} 004390050991$

Soares ML, Coelho T, Sousa A, Holmgren G, Saraiva MJ, Kastner DL, Buxbaum JN. Haplotypes and DNA sequence variation within and surrounding the transthyretin gene: genotype-phenotype correlations in familial amyloid polyneuropathy (V30M) in Portugal and Sweden. Eur J Hum Genet. 2004;12:225-37. PMID: 14673473 DOI: $10.1038 /$ sj.ejhg. 5201095

Soares ML, Coelho T, Sousa A, Batalov S, Conceição I, Sales-Luís ML, Ritchie MD, Williams SM, Nievergelt CM, Schork NJ, Saraiva MJ, Buxbaum JN. Susceptibility and modifier genes in Portuguese transthyretin V30M amyloid polyneuropathy: complexity in a single-gene disease. Hum Mol Genet. 2005;14:543-53. PMID: 15649951 DOI: $10.1093 / \mathrm{hmg} / \mathrm{ddi} 051$

Sousa A, Coelho T, Barros J, Sequeiros J. Genetic epidemiology of familial amyloidotic polyneuropathy (FAP)-type I in Póvoa de Varzim and Vila do Conde (North of Portugal). Am J Med Genet. 1995;60:512-21. PMID: 8825887 DOI: $10.1002 /$ ajmg.1320600606

Sousa MM, Cardoso I, Fernandes R, Guimarães A, Saraiva MJ. Deposition of transthyretin in early stages of familial amyloidotic polyneuropathy: evidence for toxicity of nonfibrillar aggregates. Am J Pathol. 2001;159:1993-2000. PMID: 11733349 DOI: $10.1016 /$ S0002-9440(10)63050-7

Sousa MM, Ferrão J, Fernandes R, Guimarães A, Geraldes JB, Perdigoto R, Tomé L, Mota O, Negrão L, Furtado AL, Saraiva MJ. Deposition and passage of transthyretin through the blood-nerve barrier in recipients of familial amyloid polyneuropathy livers. Lab Invest. 2004;84:86573. PMID: 15122304 DOI: 10.1038/labinvest. 3700107 
Sousa M, Cremades N, Silva J, Oliveira C, Ferraz L, Teixeira da Silva J, Viana P, Barros A. Predictive value of testicular histology in secretory azoospermic subgroups and clinical outcome after microinjection of fresh and frozen-thawed sperm and spermatids. Hum Reprod. 2002;17:1800-10. PMID: 12093843 DOI: 10.1093/humrep/17.7.1800

Tallman JF, Cassela J, Kehne J. Mechanism of action of anxiolytics. In: Davis KL, Charney D, Coyle JT, Nemeroff $C$, eds. Neuropharmacology: The fifth generation of progress. Chapter 68. Brentwood: American College of Neuropsychopharmacology. 2002. p. 993-1006. DOI: 10.1002/hup.431

Teixeira AC, Saraiva MJ. Presence of N-glycosylated transthyretin in plasma of V30M carriers in familial amyloidotic polyneuropathy: an escape from ERAD. J Cell Mol Med. 2013;17:429-35. PMID: 23387326 DOI: $10.1111 / \mathrm{jcmm} .12024$

Teixeira PF, Cerca F, Santos SD, Saraiva MJ. Endoplasmic reticulum stress associated with extacellular aggregates. Evidence from transthyretin deposition in familial amyloid polyneuropathy. J Biol Chem. 2006;281:21998-2003. PMID: 16751191 DOI: $10.1074 /$ jbc.M602302200

Tesarik J, Sousa M, Testart J. Human oocyte activation after intracytoplasmic sperm injection. Hum Reprod. 1994;9:511-8. PMID: 8006144 DOI: http://dx.doi. org/10.1093/oxfordjournals. humrep.a138537

Tesarik J, Sousa M. Key elements of a highly efficient intracytoplasmic sperm injection technique: $\mathrm{Ca} 2+$ fluxes and oocyte cytoplasmic dislocation. Fertil Steril. 1995;64:770-6. PMID: 7672149 DOI: http://dx.doi. org/10.1093/oxfordjournals. humrep.a138537
Tezer M, Ozluk Y, Sanli O, Asoglu O, Kadioglu A. Nitric oxide may mediate nipple erection. J Androl. 2012;33:805-10. PMID: 22207705 DOI: 10.2164/jandrol.111.014951

Valdrez K, Alves E, Coelho T, Silva S. Prevalence of use of preimplantation genetic diagnosis in Unidade Clínica de Paramiloidose from Centro Hospitalar do Porto. Acta Med Port. 2014a;27:710-6. PMID: 25641285

Valdrez K, Silva S, Coelho T, Alves E. Awareness and motives for use and non-use of pre-implantation genetic diagnosis in familial amyloid polyneuropathy mutation carriers. Prenat Diagn. 2014b; 34:886-92. PMID: 24752805 DOI: $10.1002 / p d .4388$

Vandervorst M, Liebaers I, Sermon K, Staessen C, De Vos A, Van de Velde $H$, Van Assche $E$, Joris $H$, Van Steeirteghem A, Devroey P. Successful preimplantation genetic diagnosis is related to the number of available cumulus-oocyte complexes. Hum Reprod. 1998;13:3169-76. PMID: 9853877 DOI: http://dx.doi.org/10.1093/humrep/13.11.3169

Wittrup A, Lieberman J. Knocking down disease: a progress report on siRNA therapeutics. Nat Rev Genet. 2015;16:543-52. PMID: 26281785 DOI: $10.1038 / \mathrm{nrg} 3978$

Yamashita T, Ando $\mathrm{Y}$, Ueda M, Okamoto S, Misumi $\mathrm{Y}$, Nakamura M, Takashi O, Uchino M. A rapid and sensitive prenatal diagnosis of familial amyloidotic polyneuropathy ATTR Val30Met by mass spectrometry. Prenat Diagn. 2009;29:930-3. PMID: 19609897 DOI: 10.1002/pd.2169 